\title{
Unraveling New Role of Ethylene Carbonate Solvation Shell in Rechargeable Metal Ion Batteries
}

Qian Li, ${ }^{\dagger \# l}$ Zhen Cao, ${ }^{\dagger}$ Wandi Wahyudi, ${ }^{\dagger}$ Gang Liu, ${ }^{\# \|}$ Geon-Tae Park, ${ }^{\ddagger}$ Luigi Cavallo, ${ }^{\S}$

Thomas D. Anthopoulos, ${ }^{\S}$ Limin Wang, ${ }^{\# \|}$ Yang-Kook Sun, ${ }^{*}$ Husam N. Alshareef, ${ }^{\S}$ Jun $\operatorname{Ming} * \# \|$

\# State Key Laboratory of Rare Earth Resource Utilization, Changchun Institute of Applied Chemistry, CAS, Changchun, 130022, China

" School of Applied Chemistry and Engineering, University of Science and Technology of China, Hefei, 230026, China

$\S$ Physical Science and Engineering Division, King Abdullah University of Science and Technology (KAUST), Thuwal, 23955-6900, Saudi Arabia

$\ddagger$ Department of Energy Engineering, Hanyang University, Seoul, 133-791, Republic of Korea

$\dagger$ These authors contribute equally

*To whom correspondence should be addressed: yksun@hanyang.ac.kr; husam.alshareef@kaust.edu.sa; jun.ming@ ciac.ac.cn. 


\section{Experimental Section}

Materials. The chemicals of lithium hexafluorophosphate ( $\left.\mathrm{LiPF}_{6}, 99.9 \%\right)$, sodium hexafluorophosphate $\left(\mathrm{NaPF}_{6}, 99.5 \%\right)$, potassium hexafluorophosphate $\left(\mathrm{KPF}_{6}, 99.9 \%\right)$, lithium bis(fluorosulfonyl)imide (LiFSI, > 99\%), lithium bis(trifluoromethanesulfonyl)imide (LiTFSI, > 98.0\%), potassium bis(fluorosulfonyl)imide (KFSI, > 95.0\%), potassium bis(trifluoromethanesulfonly)imide (KTFSI, 97\%), ethylene carbonate (EC, 99.95\%), dimethyl carbonate (DMC, 99.95\%), ethyl methyl carbonate (EMC, 99.9\%), and diethyl carbonate (DEC, 99.98\%) were purchased from DodoChem. The metal salt was vacuum dried at $100{ }^{\circ} \mathrm{C}$ before transferring to the glovebox. The solvent was treated by the molecular sieve in the glove box to remove the traces of water.

Electrolyte Preparation and Characterizations. The stoichiometric ratio of lithium, sodium, or potassium salt was dissolved in different carbonate solvents under stirring to prepare the targeted electrolytes based on the concentration. The Raman spectra of electrolytes were collected by the Witec alpha 300R Raman spectrometer with a $514 \mathrm{~nm}$ excitation wavelength, where the laser was focused on the electrolyte that was filled in the cuvette. The Nuclear magnetic resonance (NMR) analysis of the electrolyte was carried out on Bruker AV-Ш $600 \mathrm{MHz}$ Liquid NMR. The residual electrolyte in the coin cell was extracted from the separator by the chloroform-d, then the diluted upper clear solution was analyzed. The morphology of the metal deposited electrode was characterized by scanning electron microscopy (SEM, Hitachi S-4800). The X-ray photoelectron spectra (XPS) of the Cu@Li-SEI electrode was measured by ESCALABMKLL with Al Ka radiation, which emits $1.4866 \mathrm{keV}$ X-ray with the corresponding wavelength of $8.53 \AA$.

Metal Plating and Plating/Stripping Characterization. The metal plating (i.e., $\mathrm{M}=\mathrm{Li}$, Na, $\mathrm{K})$ was characterized using the metal $\mid \mathrm{Cu}$ half-cell, in which different kinds of electrolyte was used to study the plating behavior. The cell was discharged at the current density of 0.05 


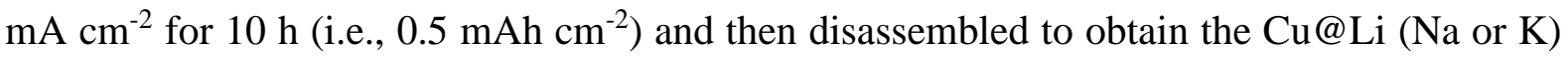
electrode. The Cu@Li electrode was washed by the DMC before the field emission scanning electron microscope (SEM, Hitachi S-4800) characterization. The plating/stripping behaviors were performed by a $\mathrm{Li}(\mathrm{Na}, \mathrm{K}) \mid \mathrm{Li}(\mathrm{Na}, \mathrm{K})$ symmetric cell, in which the current density and the total capacity was set at $0.5 \mathrm{~mA} \mathrm{~cm}^{-2}$ and $0.5 \mathrm{mAh} \mathrm{cm}^{-2}$.

SEI Effect Characterizations. The requested amount of lithium (i.e., $4 \mathrm{mAh} \mathrm{cm}^{-2}$ and $\sim 1.0$ $\mathrm{mAh} \mathrm{cm}^{-2}$ ) was plated on the $\mathrm{Cu}$ foil through two battery schemes of NCM523 | Cu and Li | $\mathrm{Cu}$ half-cell. In the first scheme, the NCM523 $\mid \mathrm{Cu}$ half-cell was charged at $0.1 \mathrm{C}(1 \mathrm{C}=280$ $\mathrm{mA} \mathrm{g}^{-1}$ ) in the selected electrolyte (e.g., 1.0 $\mathrm{M} \mathrm{LiPF}_{6}$ in EC/DEC, or EC/EMC) first. Then, the Cu@Li-SEI electrode was disassembled and reassembled into a new Cu@Li-SEI | $\mathrm{Cu} @ \mathrm{Li}-\mathrm{SEI}$ symmetric cell using different kinds of electrolyte (e.g., 1.0 M LiPF 6 in DEC, EMC, EC/DEC, or EC/EMC). In the second scheme of $\mathrm{Li} \mid \mathrm{Cu}$ half-cell, the cell was discharged at $0.2 \mathrm{~mA} \mathrm{~cm}^{-2}$ for $20 \mathrm{~h}$ to get the $\mathrm{Cu} @ \mathrm{Li}-\mathrm{SEI}$, and then the same procedures were carried out to assemble the $\mathrm{Cu} @$ Li-SEI | Cu@Li-SEI symmetric cell. Note that the asprepared $\mathrm{Cu} @$ Li-SEI electrode was washed carefully by DMC to remove the residual electrolyte and then vacuum dried slowly in a glove box at room temperature before assembling a new battery. The entire process was handled carefully in the glovebox, where the moisture and oxygen contents are controlled at below $0.5 \mathrm{ppm}$. Such an exchange experiment has been well-established and widely used in our recent researches, ${ }^{\text {S1-S4 }}$ in which the broken and partial dissolution of SEI are very limited.

Density Functional Theory Simulation. The simulations were performed at the PBE0 level of DFT calculations for the EC, DMC, EMC and DEC molecules and their anions with -1 charge. We used the DEF2TZVP basis set implemented in the Gaussian09 package. The energies of the LUMO of these organic molecules and the HOMO of their anionic partners were obtained for the analysis. 

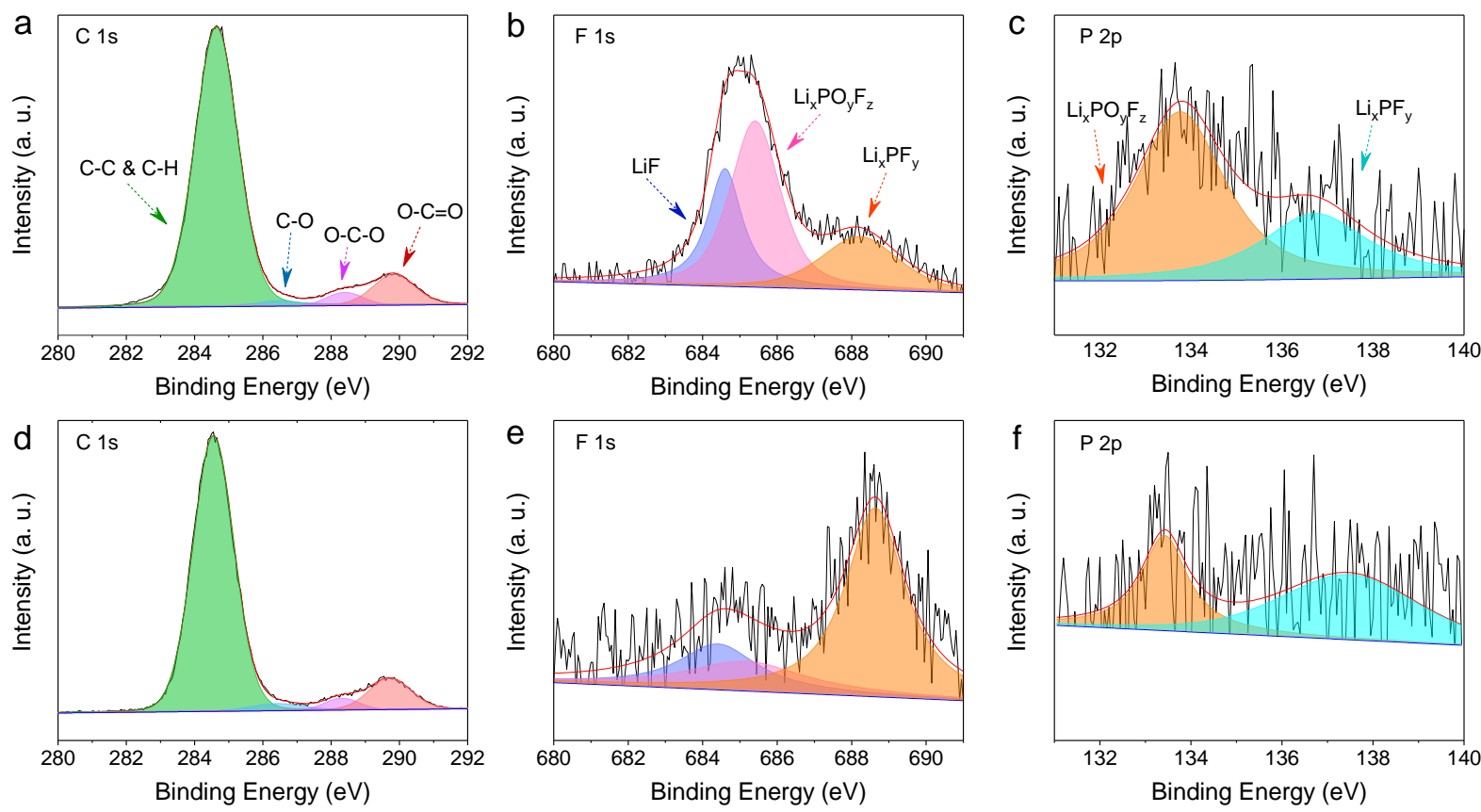

Figure S1. X-ray photoelectron spectroscopy (XPS) of the Cu@Li-SEI electrode. The C 1s, F1s, and P 2p spectrum of Cu@Li-SEI electrode that formed in the (a-c) NCM523 | Cu cell and (d-f) $\mathrm{Li} \mid \mathrm{Cu}$ cell, respectively. We find that the compositions of the SEI component are different. A higher amount of $\mathrm{Li}_{\mathrm{x}} \mathrm{PO}_{\mathrm{y}} \mathrm{F}_{\mathrm{z}}$ was observed in the $\mathrm{Cu} @ \mathrm{Li}-\mathrm{SEI}$ electrode that was formed in the NCM523 | Cu cell. This is because an anion-induced (i.e., $\mathrm{PF}_{6}^{-}$) electrolyte decomposition (i.e., oxidation process) was triggered at a high-voltage charging process. 
a

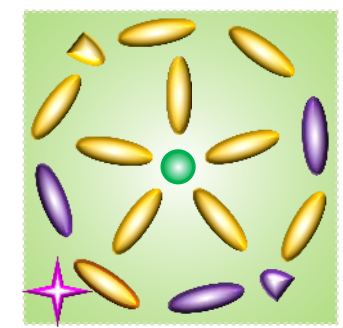

$\mathrm{Li}^{+}[\mathrm{EC}]_{10.37}\left[\mathrm{EMC}_{3.24}\left[\mathrm{PF}_{6}^{-}\right]\right.$

$1.0 \mathrm{M} \mathrm{LiPF}_{6}$ in EC/EMC $(2 / 1, \mathrm{v} / \mathrm{v})$ b

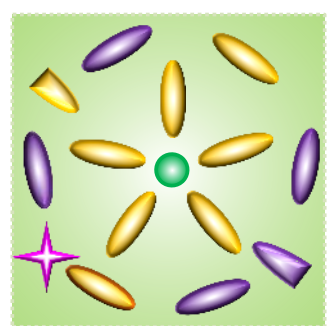

$\mathrm{Li}^{+}[\mathrm{EC}]_{7.78}[\mathrm{EMC}]_{4.87}\left[\mathrm{PF}_{6}-\right]$

1.0 M LiPF ${ }_{6}$ in EC/EMC $(1 / 1, v / v)$

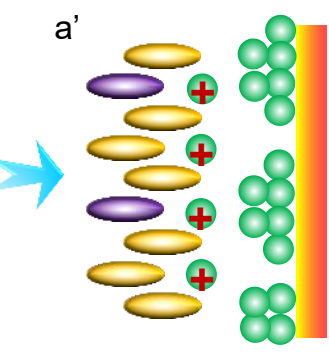

C

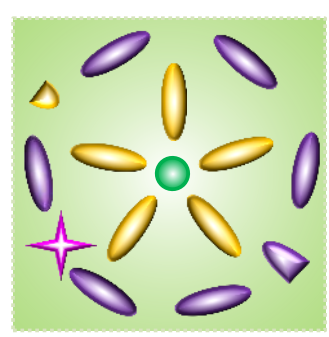

$\mathrm{Li}^{+}[\mathrm{EC}]_{5.19}\left[\mathrm{EMC}_{6.49}\left[\mathrm{PF}_{6}^{-}\right]\right.$

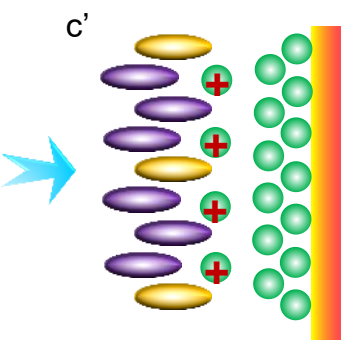

$1.0 \mathrm{M} \mathrm{LiPF}_{6}$ in EC/EMC $(1 / 2, \mathrm{v} / \mathrm{v})$

Figure S2. Comparative $\mathrm{Li}^{+}$solvation structure and interfacial model of lithium deposition in different electrolytes. The electrolyte is $1.0 \mathrm{M} \mathrm{LiPF}_{6}$ in EC/EMC, in which the volumetric ratio of the EC/EMC was controlled at (a, a') 2/1, (b, b') 1/1, and (c, c') 1/2. The corresponding formula of the $\mathrm{Li}^{+}$solvation structure is $\mathrm{Li}^{+}[\mathrm{EC}]_{10.37}\left[\mathrm{EMC}_{3.24}\left[\mathrm{PF}_{6}^{-}\right]\right.$, $\mathrm{Li}^{+}[\mathrm{EC}]_{7.78}\left[\mathrm{EMC}_{4.87}\left[\mathrm{PF}_{6}{ }^{-}\right]\right.$, and $\mathrm{Li}^{+}[\mathrm{EC}]_{5.19}\left[\mathrm{EMC}_{6.49}\left[\mathrm{PF}_{6}{ }^{-}\right]\right.$, respectively. A large size and not uniform lithium particles were deposited when the EC is dominant in the EC/EMC (2/1)based electrolyte. A small size and uniform lithium particles were deposited when the volumetric ratio of $\mathrm{EC} / \mathrm{EMC}$ in the electrolyte is controlled at 1/1. An intermediate size, uniform but fluffy lithium particles were deposited when the EMC is dominant in the EC/EMC (1/2)-based electrolyte. The reason should be ascribed to the different interfacial models tuned by the volumetric ratio of EC/EMC solvent. 

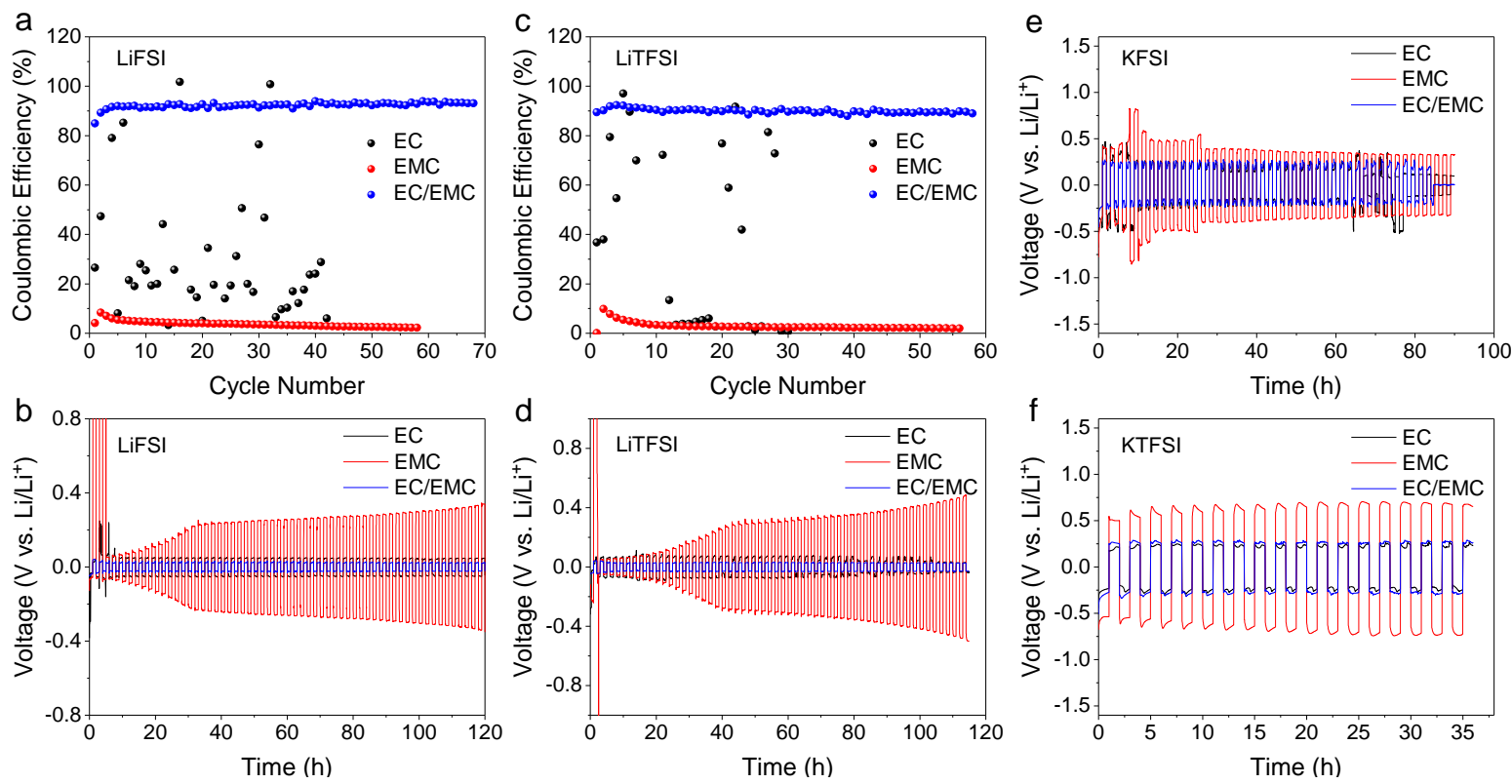

Figure S3. Demonstration of the stabilization effect of EC solvent in the electrolytes using different anions. Comparative Coulombic efficiency tested in $\mathrm{Li} \mid \mathrm{Cu}$ asymmetric halfcell and voltage $v s$. time profiles tested in $\mathrm{Li} \mid \mathrm{Li}$ symmetric cell using different lithium salt of (a, b) 1.0 M LiFSI and (c, d) 1.0 M LiTFSI in the electrolyte. Comparative voltage vs. time profiles tested in $\mathrm{K} \mid \mathrm{K}$ symmetric cell using different potassium salt of (e) 1.0 M KFSI and (f) 1.0 M KTFSI in the electrolyte. We find that the electrochemical performances are much better when the EC solvent was added as the co-solvent into the EMC-based electrolyte. 

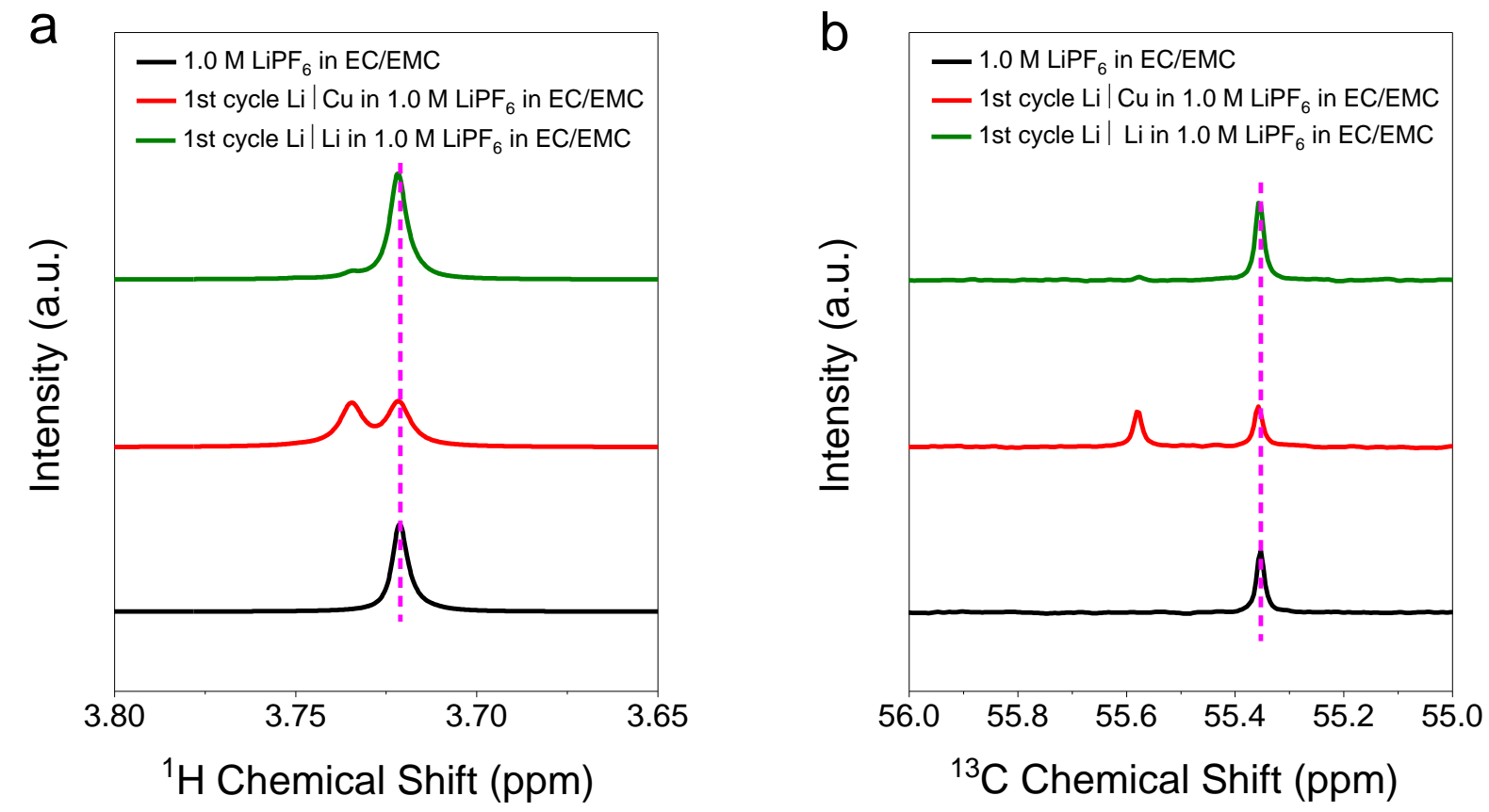

Figure S4. Electrolyte characterizations. (a) ${ }^{1} \mathrm{H}-\mathrm{NMR}\left(-\mathrm{OCH}_{3}\right)$ and (b) ${ }^{13} \mathrm{C}-\mathrm{NMR}\left(-\mathrm{OCH}_{3}\right)$ spectroscopy of the pristine electrolyte of $1.0 \mathrm{M} \mathrm{LiPF}_{6}$ in EC/EMC and residual electrolyte collected after the $1^{\text {st }}$ cycle in the $\mathrm{Li} \mid \mathrm{Li}$ symmetric cell and $\mathrm{Li} \mid \mathrm{Cu}$ half-cell. 


\section{References}

(S1) Ming, J.; Cao, Z.; Wu, Y.; Wahyudi, W.; Wang, W.; Guo, X.; Cavallo, L.; Hwang, J.-Y.; Shamim, A.; Li, L. J.; Sun, Y. K.; Alshareef, H. N. New Insight on the Role of Electrolyte Additives in Rechargeable Lithium Ion Batteries. ACS Energy Lett. 2019, 4, 2613-2622.

(S2) Liu, G.; Cao, Z.; Zhou, L.; Zhang, J.; Sun, Q.; Hwang, J. Y.; Cavallo, L.; Wang, L.; Sun, Y. K.; Ming, J. Additives Engineered Nonflammable Electrolyte for Safer Potassium Ion Battery. Adv. Funct. Mater. 2020, 2001934-2001941.

(S3) Zhou, L.; Cao, Z.; Zhang, J.; Sun, Q.; Wu, Y.; Wahyudi, W.; Hwang, J. Y.; Wang, L.; Cavallo, L.; Sun, Y. K.; Alshareef, H. N.; Ming, J. Engineering Sodium-Ion Solvation Structure to Stabilize Sodium Anodes: Universal Strategy for Fast-Charging and Safer Sodium-Ion Batteries. Nano Lett. 2020, 20, 3247-3254.

(S4) Zhang, J.; Cao, Z.; Zhou, L.; Liu, G.; Park, G. T.; Cavallo, L.; Wang, L.; Alshareef, H. N.; Sun, Y. K.; Ming, J. Model-Based Design of Graphite-Compatible Electrolytes in Potassium-Ion Batteries. ACS Energy Lett. 2020, 5, 2651-2661. 